\title{
Глава 5
}

\section{МЕХАНИЗМЫ ИЗМЕНЕНИЯ ДИНАМИЧЕСКОЙ СЛОЖНОСТИ ПАТТЕРНОВ ЭЭГ ПРИ НАРУШЕНИИ СЕРДЕЧНОГО РИТМА}

\section{1. Нелинейная динамика паттернов ЭЭГ человека при нарушении сердечного ритма}

В связи со старением населения постоянно увеличивается число людей с нарушениями сердечного ритма, в частности возрастает риск возникновения мерцательной аритмии [153]. Нарушения гемодинамики и тромбоэмболические осложнения, связанные с хронической мерцательной аритмией (фибрилляцией предсердий постоянного типа), повышают риск возникновения ишемического инсульта и даже смерти [154-156]. При пароксизмальной форме фибрилляции предсердий нарушение сердечного ритма может проходить самостоятельно или под действием лекарств, однако по мере прогрессирования заболевания возможен переход пароксизмальной формы в постоянную [157].

В соответствии с многочисленными наблюдениями существует прямая связь между нарушением деятельности сердечно-сосудистой и нервной систем [158-160]. При этом отмечается четкая зависимость степени снижения когнитивных функций ЦНС от времени существования нарушения сердечного ритма, т.е. от постоянной или пароксизмальной форм фибрилляции предсердий [161-164]. Отмечается также, что фибрилляция предсердий увеличивает риск снижения когнитивных функций и развития деменции независимо от клинически явного инсульта и базовой когнитивной функции $[165$, 166]. В связи с этим для пациентов с мерцательной аритмией важной является оценка функционального состояния не только сердечно-сосудистой системы, но и нервной системы. В то же время выявление изменений в паттернах электроэнцефалограммы при заболеваниях сердца, как и при сосудистых заболеваниях мозга, затруднено в силу отсутствия специфичности ЭЭГ у таких пациентов. В данных случаях использование функциональных нагрузок и количественная оценка функционального состояния нервной системы на основе анализа нелинейной динамики реактивных паттернов ЭЭГ у лиц с фибрилляцией 
предсердий пароксизмального и постоянного типов может помочь выявить степень патологических проявлений в ЦНС и оценить перестройку электрической активности мозга в соответствии с частотой, равной или кратной частоте световых импульсов.

Для сравнения динамики светового стимула и паттерна ЭЭГ во время действия этого стимула может быть использовано оценивание кросс-вейвлетного спектра, определяющего локальные соотношения между двумя сигналами в определенные моменты времени на определенных частотах, и вейвлет-когерентности этих сигналов. Для оценивания реакции усвоения ритма возможно также применение метода совместного рекуррентного анализа, позволяющего визуализировать определенные закономерности в двух сигналах [70].

\section{2. Оченка кросс-вейвлетных спектров светового сигнала и реактивного паттерна ЭЭГ при фибрилляциях предсердий пароксизмального и постоянного типа}

Пример светового сигнала частотой 8 Гц и реактивного паттерна ЭЭГ во время фотостимуляции здорового человека показаны на рис. 5.1, a, 6, а также кросс-
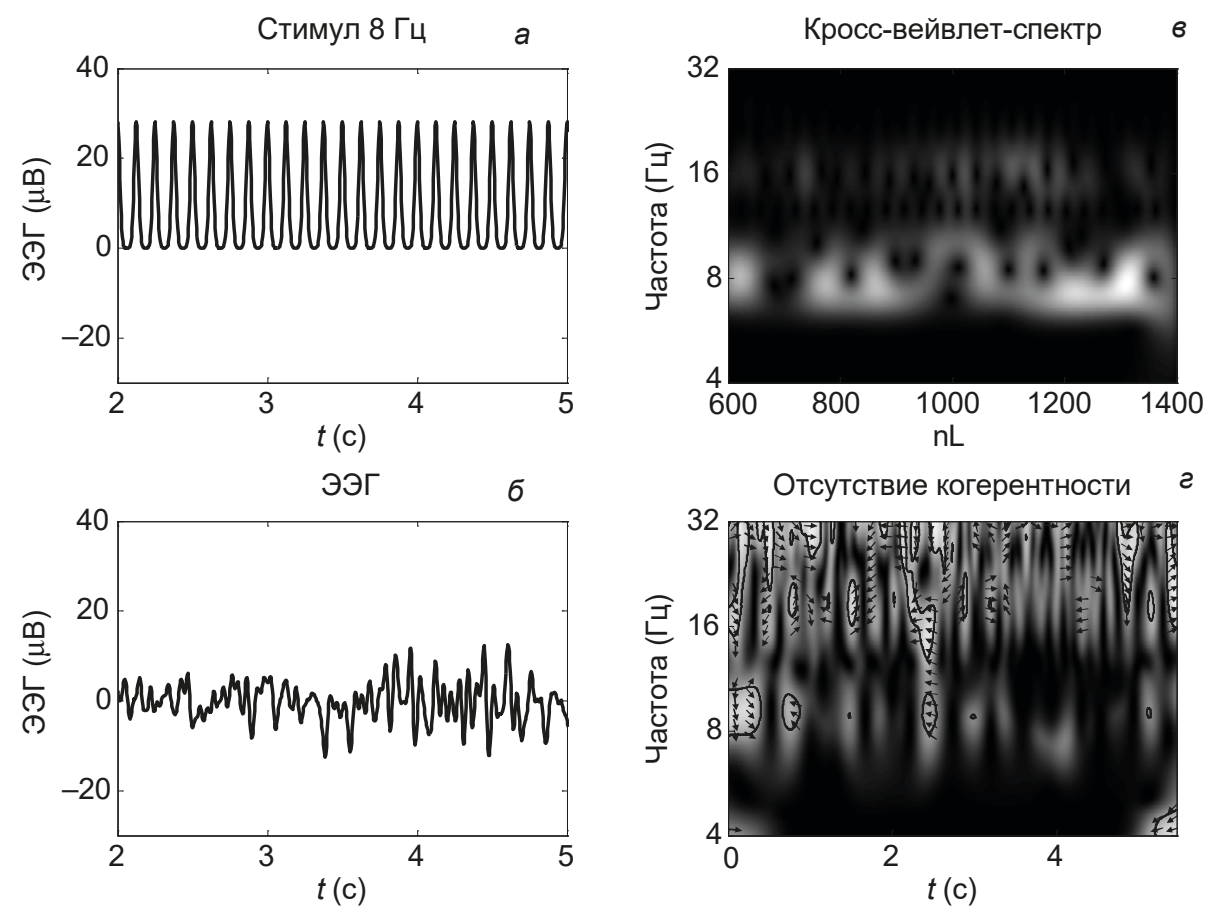

Puc. 5.1. Паттерны светового сигнала частотой 8 Гц и ЭЭГ: $a$, 6 - во время фотостимуляции здорового человека; в - кросс-вейвлет-спектр; г - вейвлет-когерентность (белый цвет означает когерентность между сигналами, черный - ее отсутствие) 
Фотостимуляция частотой 8 Гц
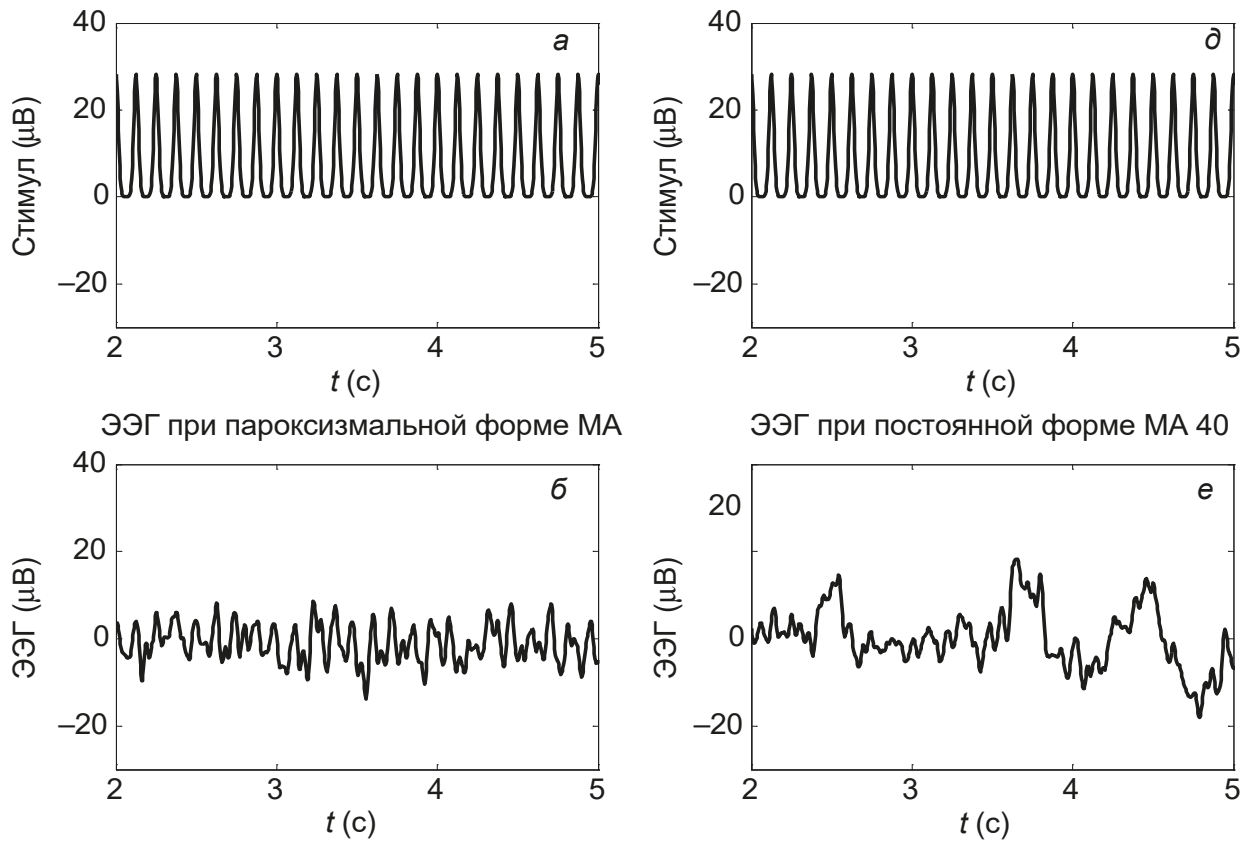

ЭЭГ при постоянной форме МА 40
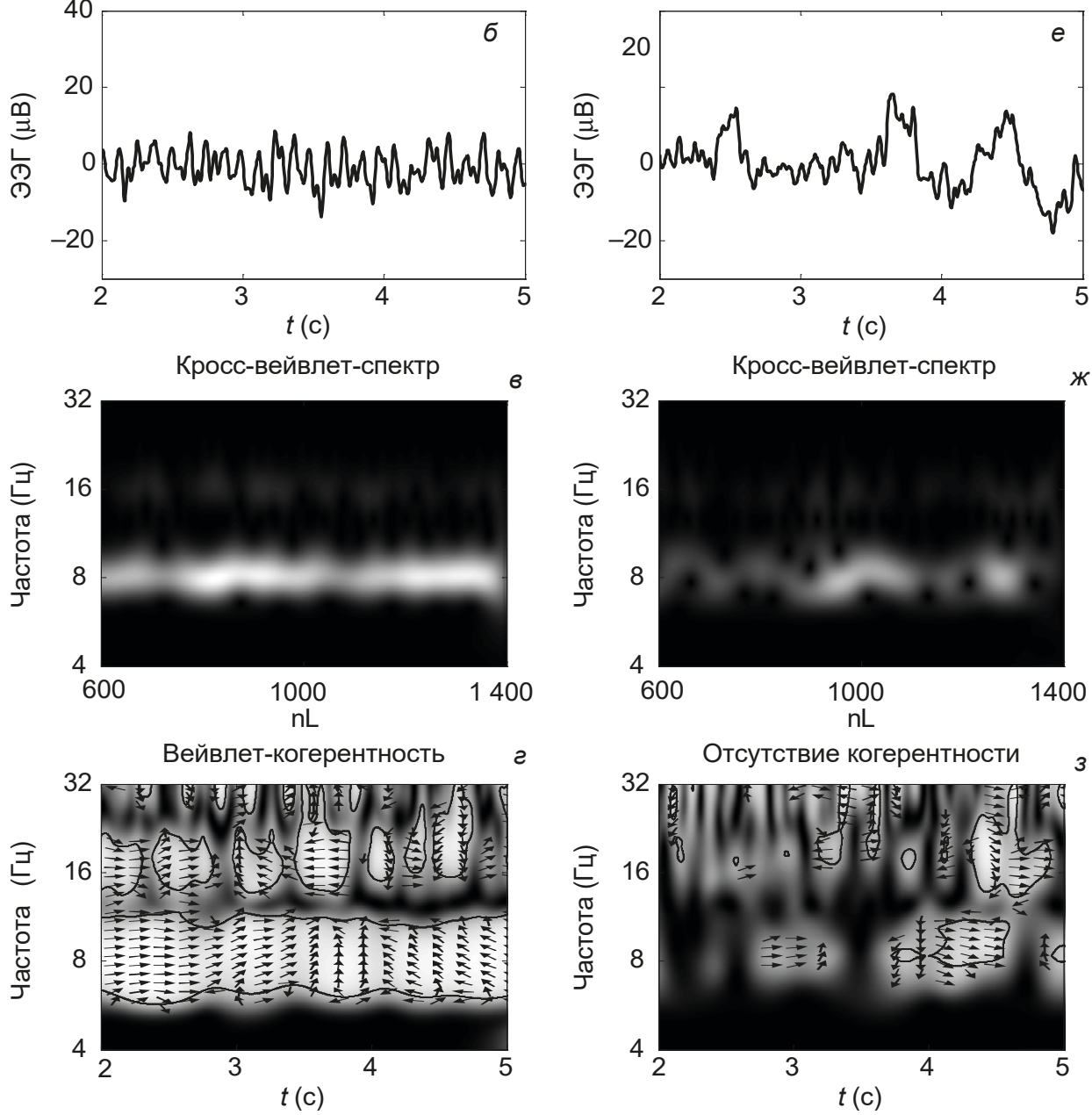

Puc. 5.2. Световой сигнал частотой 8 Гц (a, d) и паттерны ЭЭГ во время фотостимуляции у пациента с мерцательной аритмией пароксизмальной (б) и постоянной (e) формы (отведение 01). Соответствующие им кросс-вейвлет-спектры (в, ж) и вейвлет-когерентности $(2,3)$ (белый цвет означает когерентность между сигналами, черный - ее отсутствие) 
вейвлет-спектры и вейвлет-когерентности этих сигналов представлены на рис. 5.1, 8, 2. Размытые светлые полосы в кросс-вейвлет-спектрах указывают на слабую ковариантность (совместное изменение) светового сигнала и физиологического ответа (рис. 5.1, в). Статистически значимой когерентности между паттерном ЭЭГ и фотостимулом заданной частоты не обнаруживается (рис. 5.1, 2). Под термином «когерентность» понимается согласованное протекание во времени колебательных процессов. Для определения статистической значимости вейвлет-когерентности каждой частоты исходный сигнал рандомизировался по методу Монте-Карло и оценивались 300 рандомизированных реализаций.

Световой сигнал частотой 8 Гц и соответствующие ему реактивные паттерны ЭЭГ во время фотостимуляции пациентов с мерцательной аритмией, пароксизмальной и постоянной формы представлены на рис. 5.2, $a, 6$, e, кросс-вейвлет-спектры и вейвлет-когерентности этих сигналов приведены на рис. 5.2, в, 2, ж, з. Узкие светлые полосы в кросс-вейвлет-спектрах в этих двух примерах указывают на ковариантность светового сигнала и паттерна ЭЭГ. Однако анализ вейвлет-когерентности обнаруживает значительную и статистически значимую когерентность только между паттерном ЭЭГ и фотостимулом заданной частоты для пациента с мерцательной аритмией пароксизмальной формы (см. рис. 5.2, 2), но не для пациента с мерцательной аритмией постоянной формы (см. рис. 5.2, 3). Это указывает на недостаточность использования только информации, заключенной в кросс-вейвлет-спектрах, и согласуется с данными работы [48], в которой также указывается на методические погрешности при оценивании кросс-вейвлет-спектров.

\section{3. Вейвлетный анализ реактивных паттернов ЭЭГ при фибрилляциях предсердий пароксизмального и постоянного типов}

Рассмотрим динамические изменения, происходящие в глобальных $E(f)$ и локальных $\left|W\left(f, t_{0}\right)\right|^{2}$ вейвлетных спектрах, а также в нормированных интегральных распределениях энергии вейвлетных спектров паттерна ЭЭГ во время действия фотостимула в узких частотных диапазонах вблизи частоты фотостимуляции.

Рис. 5.3 демонстрирует слабую реакцию усвоения частоты 10 Гц в паттерне ЭЭГ обследуемого человека из контрольной группы. Наличие реакции усвоения ритма заданной частоты определяется по увеличению энергии $E(f)$ (рис. 5.3, a, б) и нарастанию интегрального распределения $E\left(t_{0}\right) / E_{\max }\left(t_{0}\right)$ во время фотостимуляции (рис. $5.3,2)$. Незначительность реакции усвоения ритма заданной частоты в анализируемом паттерне ЭЭГ оценивается величиной коэффициента усвоения ритма $\left(k_{R}\right)$, значение которого близко к 1. 

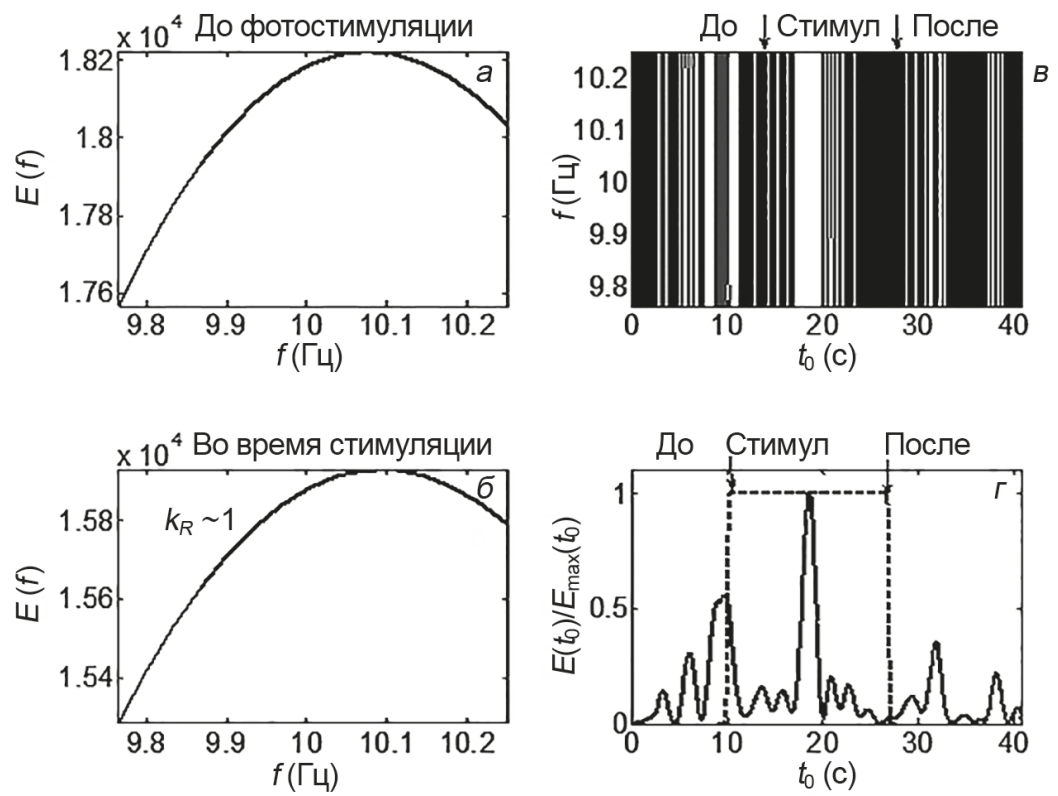

PUс. 5.3. Слабая реакция усвоения частоты 10 Гц в паттерне ЭЭГ эдорового человека: $a, 6$ - глобальный вейвлетный спектр $E(f)$ до и во время действия фотостимула: в - локальный вейвлетный спектр $\left|W\left(f, t_{0}\right)\right|^{2}$ паттерна; г - нормированные интегральные распределения энергии вейвлетных спектров паттерна и фотостимула (сплошная и штрихпунктирная линии)

Пример выраженной реакции на частоту 8 Гц у пациента с мерцательной аритмией пароксизмальной формы представлен на рис. 5.4, где наблюдается значительное нарастание энергии глобального вейвлетного спектра во время действия фотостимула (рис. $5.4, a, 6$ ). Максимум локального вейвлетного спектра достигается в конце интервала фотостимуляции (рис. 5.4, 8), т. е. в данном паттерне происходит медленное нарастание энергии вейвлетного спектра вблизи заданной частоты (рис. 5.4, 2).

Пример незначительной реакции усвоения ритма частоты фотостимуляции 12 Гц у пациента с мерцательной аритмией постоянной формы приведен на рис. 5.5. Во время действия фотостимула происходит небольшое увеличение энергии глобального вейвлетного спектра (рис. 5.5, a, б). Локальный вейвлетный спектр достигает максимума в середине интервала фотостимуляции (рис. $5.5,8$ ), т. е. наблюдается быстрое нарастание энергии вейвлетного спектра и затем ее уменьшение (рис. 5.5, 2). 

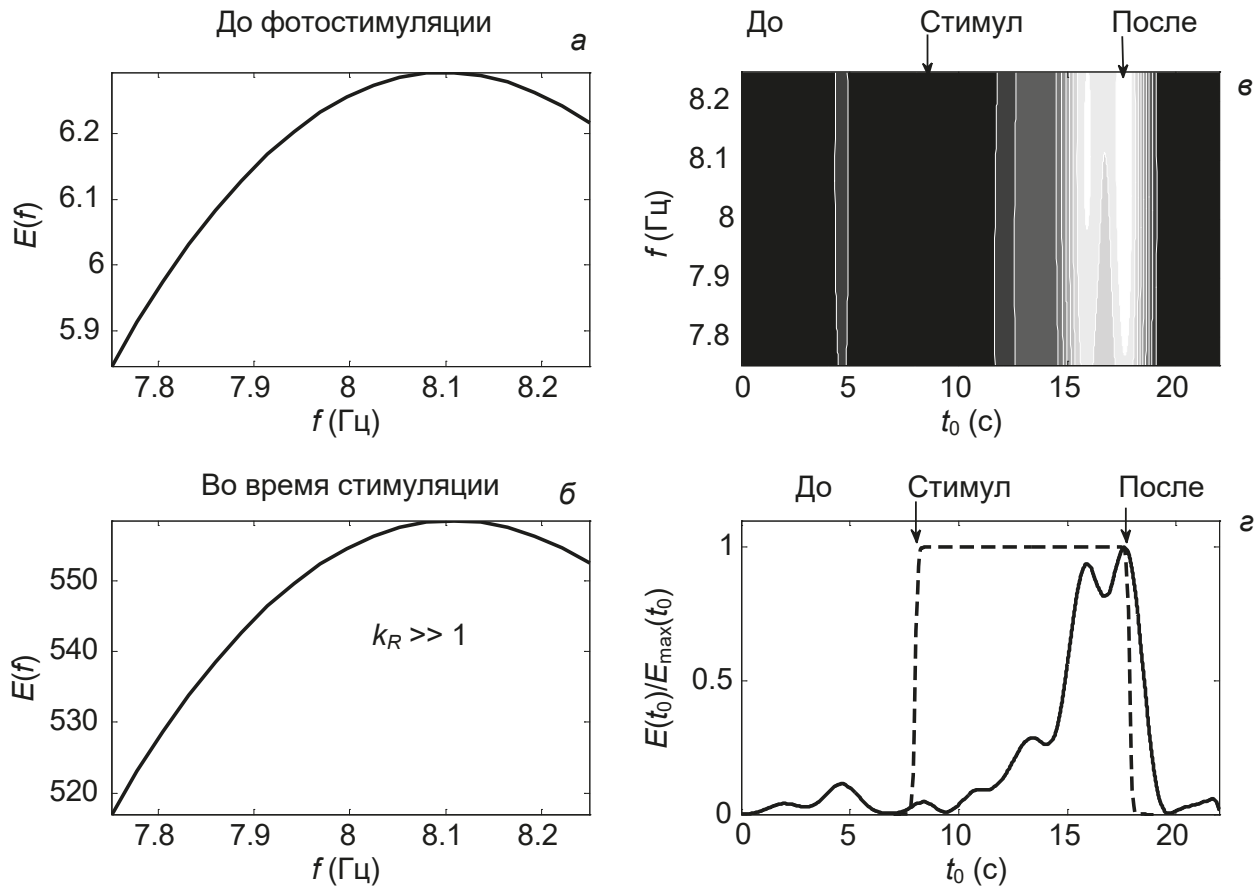

Puc. 5.4. Пример выраженной реакции на частоту 8 Гц у пациента с мерцательной аритмией пароксизмальной формы
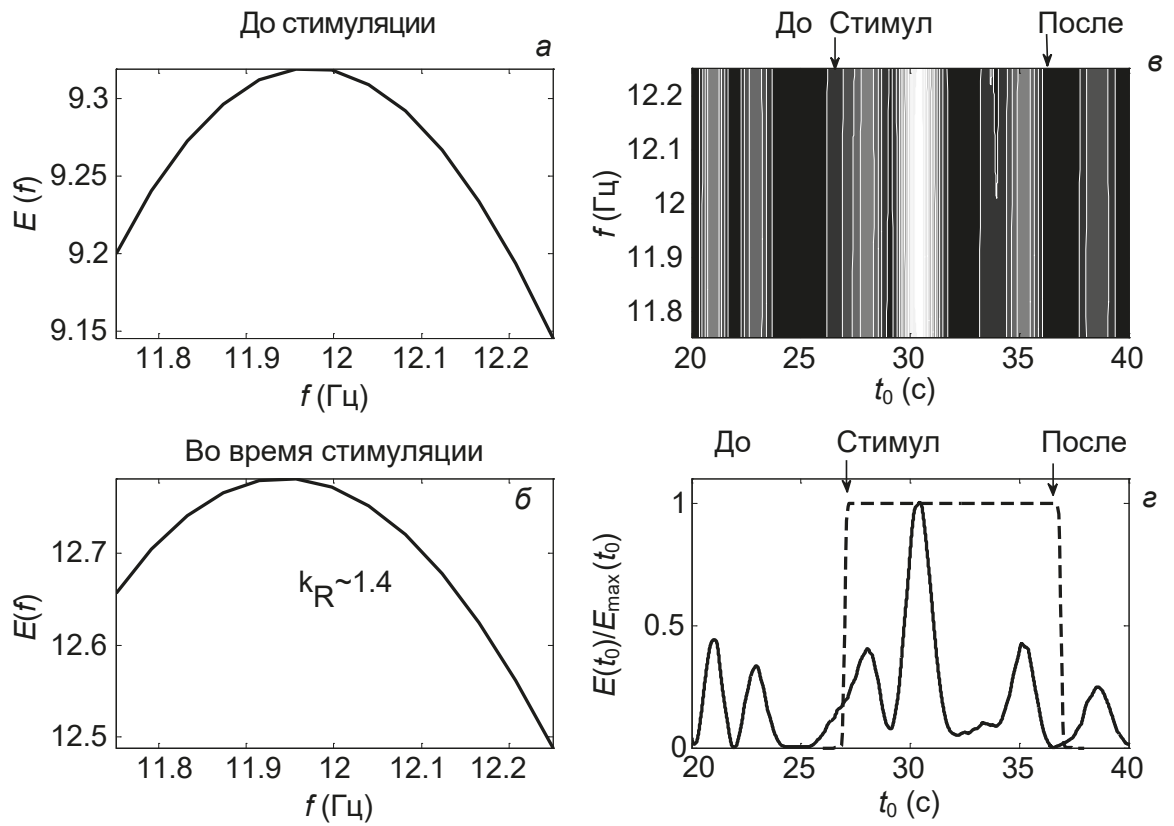

Puc. 5.5. Пример слабой реакции на частоту 12 Гц у пациента с мерцательной аритмией постоянной формы 


\section{4. Оченка реакции усвоения ритма в паттернах ЭЭГ}

у пациентов с фибрилляцией предсердий на основании анализа рекуррентных диаграмм

Еще одним доказательством наличия реакции усвоения ритма в паттернах ЭЭГ у пациентов с фибрилляцией предсердий является присутствие одновременных рекуррентностей в совместных рекуррентных диаграммах этих паттернов и ритмических световых сигналов определенных частот. Примеры таких диаграмм для пациентов с мерцательной аритмией пароксизмальной и постоянной форм представлены на рис. 5.6, 6, г соответственно. Эти диаграммы построены при величине временной задержки $d=5$ и размерности вложения $m=3$, величина размера окрестности $\varepsilon$ равна $1 \%$ от величины стандартного отклонения анализируемых временных рядов. Паттерны ЭЭГ во время фотостимуляции частотой 12 Гц показаны на рис. 5.6, $a, 6$.

Диаграмма на рис. 5.6, 6 содержит рекуррентные структуры с различными расстояниями между диагональными линиями, которые группируются в не-
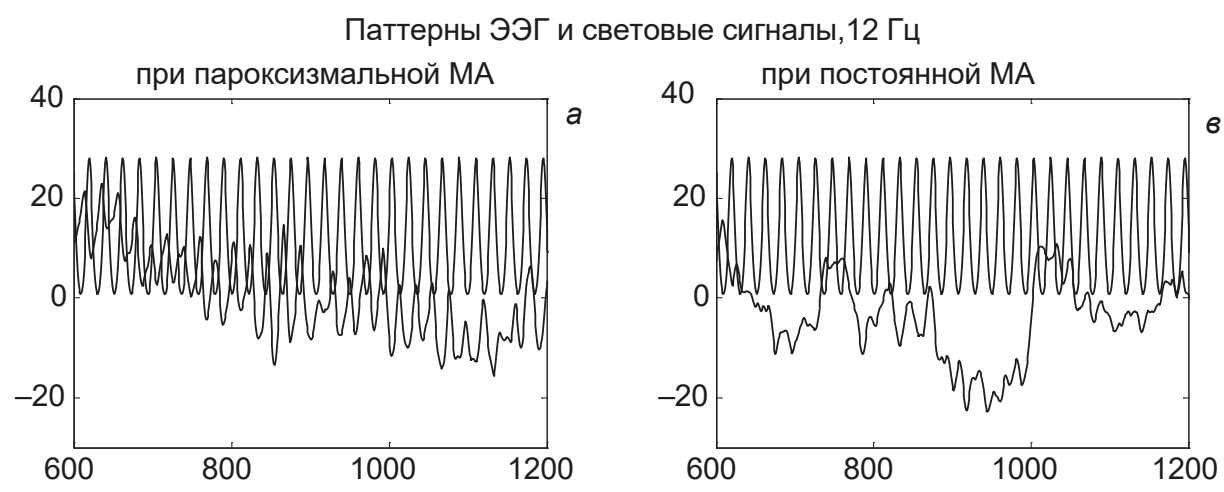

Совместные рекуррентные диаграммы
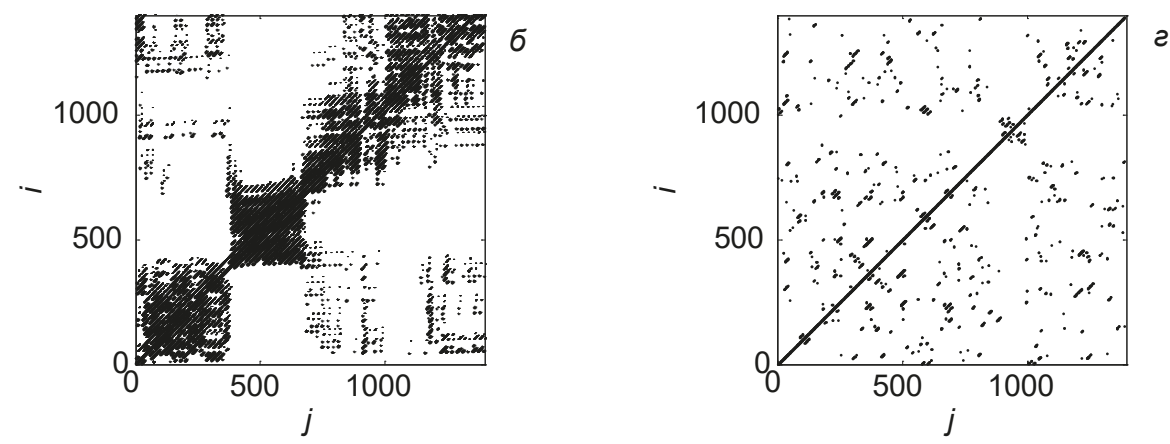

Puc. 5.6. Примеры паттернов ЭЭГ во время фотостимуляции пациентов с мерцательной аритмией пароксизмальной (a) и постоянной (в) форм; совместные рекуррентные диаграммы этих паттернов и световых сигналов $(6,2)$ 
регулярные черные кластеры, что свидетельствует о возникновении одновременных рекуррентностей в паттерне ЭЭГ у пациента с мерцательной аритмией пароксизмальной формы и световом сигнале заданной частоты. В отличие от этого диаграмма на рис. 5.6, г содержит только редкие и короткие диагональные линии, т.е. почти не имеет совместных рекуррентностей в анализируемом паттерне пациента с фибрилляцией предсердий постоянной формы и данном световом сигнале.

Представленные на рис. 5.2-5.6 реакции усвоения ритма заданных частот были характерны не менее чем для $92 \%$ лиц из каждой обследуемой группы, что позволило нам при дальнейших количественных оценках использовать усреднение значений полученных параметров по числу испытуемых в каждой группе.

\section{5. Оценка различий в функциональном состоянии ЦнС у пациентов с нарушениями сердечного ритма в виде мерцательной аритмии пароксизмального и постоянного типов}

Усредненные (по числу испытуемых в каждой группе) значения коэффициентов усвоения $\left(k_{\mathrm{R}}\right)$ и удержания $\left(k_{\mathrm{H}}\right)$ ритма заданной частоты, а также времени запоминания ритма $\left(T_{\text {incr }}\right)$ для реактивных паттернов различных групп обследованных лиц приведены в табл. 5.1. У всех тестируемых пациентов отсутствуют статистически значимые различия в средних значениях параметров, вычисленных для затылочных отведений $\mathrm{O} 1$ и $\mathrm{O} 2\left(p_{2}>0,05\right)$. Это говорит об отсутствии асимметрии реакции усвоения ритма.

Для 9 из 10 лиц контрольной группы значение коэффициента усвоения ритма $k_{\mathrm{R}}<1$ во всех частотных диапазонах, что означает отсутствие нарастания энергии во время фотостимуляции. Незначительное усвоение выявляется только для частот 10 и 12 Гц ( $k_{\mathrm{R}}=1,31 \pm 0,06$ и $k_{\mathrm{R}}=1,16 \pm 0,04$ соответственно). Удержание ритма заданной частоты также незначительно $\left(k_{\mathrm{H}}=0,12 \pm 0,01\right.$ и $\left.k_{\mathrm{H}}=0,11 \pm 0,01\right)$, а время запоминания ритма максимально $\left(T_{\mathrm{incr}}=6,1 \pm 0,3 \mathrm{c}\right.$ и $\left.T_{\text {incr }}=5,4 \pm 0,3 \mathrm{c}\right)$.

Для пациентов с мерцательной аритмией ответы на реакцию фотостимуляции значительно отличаются от ответов в контрольной группе на уровне значимости $p_{1}<0,05$ по тесту Манна - Уитни. Прежде всего в паттернах ЭЭГ у 15 из 16 лиц с фибрилляцией предсердий пароксизмального типа и у 20 из 22 лиц с фибрилляцией предсердий постоянного типа отмечается усвоение частот тета-диапазона. Например, для лиц с пароксизмальным типом мерцательной аритмии коэффициент усвоения ритма частоты 6 Гц $k_{\mathrm{R}}=63 \pm 5$, а коэффициент удержания ритма $k_{\mathrm{H}}=0,11 \pm 0,01$, что говорит о том, что, несмотря на значительную реакцию, удержание ритма небольшое. В отличие от этого в группе лиц с мерцательной аритмией постоянного типа реакция усвоения ритма тета-диапазона значительно сильнее. Для той же частоты 6 Гц 
Таблица 5.1. Усредненные значения коэффициентов усвоения $\left(k_{\mathrm{R}}\right)$ и удержания $\left(k_{\mathrm{H}}\right)$ ритма заданной частоты, а также времени запоминания ритма ( $\left.T_{\text {incr }}\right)$ в исследуемых паттернах ЭЭГ

\begin{tabular}{|c|c|c|c|c|c|}
\hline Отведение & Диапазон & $k_{\mathrm{R}}$ & $T_{\text {incr }}$ & $k_{\mathrm{H}}$ & $\begin{array}{c}\text { Реакция } \\
\text { усвоения }\end{array}$ \\
\hline \multicolumn{6}{|c|}{ Контроль ( $N=9$ из 10) } \\
\hline \multirow{3}{*}{ O1 } & Альфа, 8 Гц & $<1$ & - & - & Отсутствует \\
\hline & 10 Гц & $1,31 \pm 0,06$ & $6,1 \pm 0,3$ & $0,12 \pm 0,01$ & \multirow{2}{*}{ Незначительная } \\
\hline & 12 Гц & $1,16 \pm 0,04$ & $5,4 \pm 0,3$ & $0,11 \pm 0,01$ & \\
\hline \multirow{3}{*}{$\begin{array}{c}\mathrm{O} 2 \\
p_{2}>0.05\end{array}$} & Альфа, 8 Гц & $<1$ & - & - & Отсутствует \\
\hline & 10 Гц & $1,27 \pm 0,05$ & $6,3 \pm 0,3$ & $0,19 \pm 0,01$ & \multirow{2}{*}{ Незначительная } \\
\hline & 12 Гц & $1,13 \pm 0,04$ & $5,8 \pm 0,3$ & $0,16 \pm 0,01$ & \\
\hline \multicolumn{6}{|c|}{ Пароксизмальная форма мерцательной аритмии (N=15 из 16) } \\
\hline \multirow{5}{*}{ O1 } & Тета, 4 Гц & $31 \pm 3$ & $4,7 \pm 0,2$ & $0,19 \pm 0,01$ & \multirow{5}{*}{ Значительная } \\
\hline & 6 Гц & $63 \pm 5$ & $4,2 \pm 0,2$ & $0,11 \pm 0,01$ & \\
\hline & Альфа, 8 Гц & $545 \pm 38$ & $5,4 \pm 0,3$ & $0,77 \pm 0,04$ & \\
\hline & $10 Г ц$ & $\begin{array}{c}302 \pm 15 \\
p_{1}=0,023\end{array}$ & $\begin{array}{c}3,8 \pm 0,2 \\
p_{1}=0,039\end{array}$ & $\begin{array}{l}0,81 \pm 0,05 \\
p_{1}=0,015\end{array}$ & \\
\hline & 12 Гц & $\begin{array}{c}475 \pm 29 \\
p_{1}=0,018\end{array}$ & $\begin{array}{c}3,2 \pm 0,1 \\
p_{1}=0,035\end{array}$ & $\begin{array}{l}0,51 \pm 0,03 \\
p_{1}=0,025\end{array}$ & \\
\hline \multirow{5}{*}{$\begin{array}{c}\mathrm{O} 2 \\
p_{2}>0,05\end{array}$} & Тета, 4 Гц & $29 \pm 3$ & $4,4 \pm 0,2$ & $0,14 \pm 0,01$ & \multirow{5}{*}{ Значительная } \\
\hline & 6 Гц & $69 \pm 6$ & $4,6 \pm 0,2$ & $0,11 \pm 0,01$ & \\
\hline & Альфа, 8 Гц & $572 \pm 41$ & $5,5 \pm 0,3$ & $0,79 \pm 0,04$ & \\
\hline & $10 Г ц$ & $\begin{array}{c}315 \pm 17 \\
p_{1}=0,019\end{array}$ & $\begin{array}{c}3,3 \pm 0,2 \\
p_{1}=0,036\end{array}$ & $\begin{array}{l}0,85 \pm 0,05 \\
p_{1}=0,017\end{array}$ & \\
\hline & 12 Гц & $\begin{array}{c}487 \pm 35 \\
p_{1}=0,017\end{array}$ & $\begin{array}{c}3,1 \pm 0,1 \\
p_{1}=0,032\end{array}$ & $\begin{array}{l}0,60 \pm 0,04 \\
p_{1}=0,025\end{array}$ & \\
\hline \multicolumn{6}{|c|}{ Постоянная форма мерцательной аритмии (N=20 из 22) } \\
\hline \multirow{5}{*}{01} & Тета, 4 Гц & $306 \pm 27$ & $4,8 \pm 0,3$ & $0,78 \pm 0,05$ & \multirow{2}{*}{ Значительная } \\
\hline & 6 Гц & $289 \pm 17$ & $3,5 \pm 0,3$ & $0,88 \pm 0,06$ & \\
\hline & Альфа, 8 Гц & $3,2 \pm 0,1$ & $5,2 \pm 0,3$ & $0,33 \pm 0,01$ & \multirow{3}{*}{ Слабая } \\
\hline & 10 Гц & $\begin{array}{c}3,9 \pm 0,2 \\
p_{1}=0,041\end{array}$ & $\begin{array}{c}4,8 \pm 0,2 \\
p_{1}=0,045\end{array}$ & $\begin{array}{l}0,21 \pm 0,01 \\
p_{1}=0,045\end{array}$ & \\
\hline & 12 Гц & $\begin{array}{c}2,7 \pm 0,1 \\
p_{1}=0,048\end{array}$ & $\begin{array}{c}3,1 \pm 0,1 \\
p_{1}=0,035\end{array}$ & $\begin{array}{l}0,25 \pm 0,01 \\
p_{1}=0.048\end{array}$ & \\
\hline
\end{tabular}




\begin{tabular}{|c|c|c|c|c|c|}
\hline Отведение & Диапазон & $k_{\mathrm{R}}$ & $T_{\text {incr }}$ & $k_{\mathrm{H}}$ & $\begin{array}{l}\text { Реакция } \\
\text { усвоения }\end{array}$ \\
\hline \multirow{5}{*}{$\begin{array}{c}\mathrm{O} 2 \\
p_{2}>0,05\end{array}$} & Тета, 4 Гц & $209 \pm 15$ & $4,7 \pm 0,2$ & $0,69 \pm 0,05$ & \multirow{2}{*}{ Значительная } \\
\hline & $6 Г ц$ & $198 \pm 10$ & $4,2 \pm 0,2$ & $0,76 \pm 0,05$ & \\
\hline & Альфа, 8 Гц & $2,9 \pm 0,1$ & $5,4 \pm 0,3$ & $0,30 \pm 0,01$ & \multirow{3}{*}{ Слабая } \\
\hline & $10 Г ц$ & $\begin{array}{c}2,4 \pm 0,1 \\
p_{1}=0,047\end{array}$ & $\begin{array}{c}3,8 \pm 0,2 \\
p_{1}=0,034\end{array}$ & $\begin{array}{l}0,23 \pm 0,01 \\
p_{1}=0,045\end{array}$ & \\
\hline & 12 Гц & $\begin{array}{c}2,3 \pm 0,1 \\
p_{1}=0,048\end{array}$ & $\begin{array}{c}3,4 \pm 0,2 \\
p_{1}=0,031\end{array}$ & $\begin{array}{l}0,27 \pm 0,01 \\
p_{1}=0,042\end{array}$ & \\
\hline
\end{tabular}

коэффициент усвоения ритма $k_{\mathrm{R}}=289 \pm 17$, а коэффициент удержания ритма $k_{\mathrm{H}}=0,88 \pm 0,06$.

Усвоение ритма частот альфа-диапазона наблюдается для обеих групп пациентов. При этом максимальное усвоение характерно для группы с мерцательной аритмией пароксизмального типа. Действительно, значения показателей реакции усвоения $\left(k_{\mathrm{R}}=545 \pm 38, T_{\mathrm{incr}}=5,4 \pm 0,3 \mathrm{c}, k_{\mathrm{H}}=0,77 \pm 0,04\right.$ для частоты 8 Гц) свидетельствуют о медленном и сильном нарастании энергии вейвлетного спектра вблизи частоты фотостимуляции при значительном удержании ритма заданной частоты. Для группы лиц с мерцательной аритмией постоянного типа получены гораздо меньшие значения коэффициентов усвоения и удержания ритма альфа-диапазона (например, $k_{\mathrm{R}}=2,7 \pm 0,1, T_{\text {incr }}=3,1 \pm 0,1 \mathrm{c}$, $k_{\mathrm{H}}=0,25 \pm 0,01$ для частоты 12 Гц), что позволяет говорить о более быстром, но слабом нарастании энергии вейвлетного спектра вблизи частоты фотостимуляции при незначительном удержании ритма заданной частоты.

Усвоение ритма бета-диапазона не характерно ни для одной из групп.

Значения численных показателей рекуррентных диаграмм (средняя длина диагональных линий $(L)$ и рекуррентное время, необходимое для возврата сигнала в $\varepsilon$-окрестность точки, в которой он был ранее $(\tau))$, даны в табл. 5.2.

Средняя длина диагональных линий максимальна для паттернов ЭЭГ пациентов с мерцательной аритмией пароксизмального типа $(L=8,5 \pm 0,8$, частота 8 Гц) и минимальна для паттернов ЭЭГ пациентов с мерцательной аритмией постоянного типа ( $L=1,9 \pm 0,2$, частота 10 Гц). Рекуррентное время также максимально для пациентов с мерцательной аритмией пароксизмального типа ( $\tau=0,85 \pm 0,08$, частота 8 Гц) и минимально для пациентов с мерцательной аритмией постоянного типа ( $\tau=0,24 \pm 0,02$, частота 10 Гц).

В контрольной группе эти показатели принимают меньшие значения. Например, $L=1,6 \pm 0,1$ и $\tau=0,18 \pm 0,02$ для частоты 12 Гц. Это свидетельствует о том, что рекуррентные диаграммы лиц контрольной группы практически 
Таблица 5.2. Усредненные значения средней длины диагональных линий (L) и рекуррентных времен ( $\tau$ ) в совместных рекуррентных диаграммах паттернов ЭЭГ и световых сигналов

\begin{tabular}{|c|c|c|c|c|}
\hline Отведение & Диапазон & L & $\tau$ & Реакция усвоения \\
\hline \multicolumn{5}{|c|}{ Контроль ( $N=9$ из 10) } \\
\hline \multirow{3}{*}{01} & Альфа, 8 Гц & - & - & Отсутствует \\
\hline & 10 Гц & $1,7 \pm 0,1$ & $0,20 \pm 0,02$ & \multirow{2}{*}{ Незначительная } \\
\hline & 12 Гц & $1,6 \pm 0,1$ & $0,18 \pm 0,02$ & \\
\hline \multirow{3}{*}{$\begin{array}{c}\mathrm{O} 2 \\
p_{2}>0,05\end{array}$} & Альфа, 8 Гц & - & - & Отсутствует \\
\hline & 10 Гц & $1,3 \pm 0,1$ & $0,19 \pm 0,01$ & \multirow{2}{*}{ Незначительная } \\
\hline & 12 Гц & $1,8 \pm 0,1$ & $0,16 \pm 0,01$ & \\
\hline \multicolumn{5}{|c|}{ Пароксизмальная форма мерцательной аритмии (N = 15 из 16) } \\
\hline \multirow{5}{*}{01} & Тета, 4 Гц & $5,3 \pm 0,5$ & $0,45 \pm 0,04$ & \multirow{5}{*}{ Значительная } \\
\hline & 6 Гц & $4,7 \pm 0,4$ & $0,40 \pm 0,04$ & \\
\hline & Альфа, 8 Гц & $8,5 \pm 0,8$ & $0,85 \pm 0,08$ & \\
\hline & 10 Гц & $\begin{array}{c}6,9 \pm 06 \\
p_{1}=0,039\end{array}$ & $\begin{array}{l}0,75 \pm 0,07 \\
p_{1}=0,015\end{array}$ & \\
\hline & 12 Гц & $\begin{array}{c}7,8 \pm 0,7 \\
p_{1}=0,035\end{array}$ & $\begin{array}{l}0,66 \pm 0,06 \\
p_{1}=0,025\end{array}$ & \\
\hline \multirow{5}{*}{$\begin{array}{c}02 \\
p_{2}>0,05\end{array}$} & Тета, 4 Гц & $4,4 \pm 0,2$ & $0,44 \pm 0,04$ & \multirow{5}{*}{ Значительная } \\
\hline & 6 Гц & $4,6 \pm 0,2$ & $0,39 \pm 0,04$ & \\
\hline & Альфа, 8 Гц & $8,1 \pm 0,8$ & $0,79 \pm 0,04$ & \\
\hline & 10 Гц & $\begin{array}{c}6,3 \pm 0,6 \\
p_{1}=0,036\end{array}$ & $\begin{array}{l}0,72 \pm 0,07 \\
p_{1}=0,017\end{array}$ & \\
\hline & 12 Гц & $\begin{array}{c}8,2 \pm 0,8 \\
p_{1}=0,032\end{array}$ & $\begin{array}{l}0,60 \pm 0,06 \\
p_{1}=0,025\end{array}$ & \\
\hline \multicolumn{5}{|c|}{ Постоянная форма мерцательной аритмии ( $N=20$ из 22) } \\
\hline \multirow{5}{*}{01} & Тета, 4 Гц & $8,1 \pm 0,8$ & $0,79 \pm 0,07$ & \multirow{2}{*}{ Значительная } \\
\hline & 6 Гц & $6,7 \pm 0,6$ & $0,59 \pm 0,06$ & \\
\hline & Альфа, 8 Гц & $2,9 \pm 0,3$ & $0,31 \pm 0,02$ & \multirow{3}{*}{ Слабая } \\
\hline & 10 Гц & $\begin{array}{c}1,9 \pm 0,2 \\
p_{1}=0,045\end{array}$ & $\begin{array}{l}0,24 \pm 0,02 \\
p_{1}=0,045\end{array}$ & \\
\hline & 12 Гц & $\begin{array}{c}2,1 \pm 0,2 \\
p_{1}=0,035\end{array}$ & $\begin{array}{l}0,28 \pm 0,02 \\
p_{1}=0,048\end{array}$ & \\
\hline
\end{tabular}




\begin{tabular}{|c|c|c|c|c|}
\hline Отведение & Диапазон & L & $\tau$ & Реакция усвоения \\
\hline \multirow{5}{*}{$\begin{array}{c}\mathrm{O} 2 \\
p_{2}>0,05\end{array}$} & Тета, 4 Гц & $8,4 \pm 0,8$ & $0,76 \pm 0,07$ & \multirow{2}{*}{ Значительная } \\
\hline & $6 Г ц$ & $6,2 \pm 0,6$ & $0,56 \pm 0,05$ & \\
\hline & Альфа, 8 Гц & $2,4 \pm 0,2$ & $0,30 \pm 0,02$ & \multirow{3}{*}{ Слабая } \\
\hline & $10 Г ц ~$ & $\begin{array}{c}1,7 \pm 0,2 \\
p_{1}=0,034\end{array}$ & $\begin{array}{l}0,23 \pm 0,02 \\
p_{1}=0,045\end{array}$ & \\
\hline & 12 Гц & $\begin{array}{c}2,3 \pm 0.2 \\
p_{1}=0,032\end{array}$ & $\begin{array}{l}0,27 \pm 0,02 \\
p_{1}=0,041\end{array}$ & \\
\hline
\end{tabular}

не содержат совместных рекуррентностей в анализируемых паттернах и световых сигналах частот альфа-диапазона.

Для реактивных паттернов ЭЭГ у лиц с мерцательной аритмией пароксизмального типа характерно наличие значительных совместных рекуррентностей для сигналов как в тета-, так и в альфа-диапазонах (см. табл. 5.2). В отличие от этого, паттернам ЭЭГ лиц с мерцательной аритмией постоянного типа свойственны рекуррентности преимущественно в тета-диапазоне.

Таким образом, для пациентов с фибрилляцией предсерий пароксизмального типа отмечается медленная и сильная реакция усвоения ритма частот альфа-диапазона и менее выраженная реакция усвоения ритма частот тетадиапазона, в то время как для пациентов с фибрилляцией постоянного типа значительно более слабая реакция для частот альфа- диапазона и выраженная реакция для частот тета-диапазона.

Возникновение одновременных рекуррентностей в паттернах ЭЭГ и световых сигналах частот тета- и альфа-диапазонов является характерной особенностью рекуррентных диаграмм пациентов с мерцательной аритмией пароксизмальной формы. Рекуррентные диаграммы лиц с фибрилляцией предсердий в постоянной форме также имеют совместные рекуррентности в паттернах ЭЭГ и световых сигналах частот тета-ритма, однако в альфа-диапазоне проявляют очень слабую рекуррентность.

Полученные результаты показывают, что отсутствие реакции усвоения ритма практически всех предложенных частот, наблюдаемое в паттернах ЭЭГ лиц контрольной группы, связано с отсутствием нарастания энергии вейвлетного спектра вблизи частоты фотостимуляции, низкой вейвлет-когерентностью и малыми рекуррентными временами и отражает сбалансированность процессов возбуждения и торможения.

В паттернах ЭЭГ пациентов двух исследованных групп с сердечно-сосудистой патологией в форме мерцательной аритмии отмечается повышение коэффициентов усвоения и удержания ритмов в тета- и альфа-диапазонах, что 
связано, вероятно, с повышением неустойчивости внутренней синхронизации нейронных ансамблей и усилением их внешней синхронизации. При этом характерное для лиц с пароксизмальной формой мерцательной аритмии значительное усвоение ритма частот как альфа-, так и тета-диапазонов, может быть связано с развитием неустойчивости нейродинамических процессов в результате появления в ЦНС патологического очага возбуждения (генератор повышенного усиления возбуждения по Крыжановскому) [152].

В отличие от этого наблюдаемая у лиц с постоянной формой мерцательной аритмии слабая реакция усвоения ритма частот альфа-диапазона и выраженная реакция усвоения ритма частот тета-диапазона может свидетельствовать о преобладании процессов торможения в нервной системе этих пациентов вследствие хронической гипоксии мозга.

Результаты наших исследований подтверждаются клиническими данными, полученными для обследуемых пациентов. Так, при нейропсихологическом тестировании были показаны более выраженные изменения когнитивных функций у больных с постоянной формой мерцательной аритмии, по сравнению с больными с пароксизмальной формой $[167,168]$. Слабая реакция на фотостимуляцию у пациентов с постоянной формой мерцательной аритмии может быть связана с уменьшением возбудимости корковых нейронов вследствие хронической гипоксии мозга. Это подтверждается фоновой ЭЭГ у этих пациентов: в фоновых паттернах выявлено преобладание тета-активности [169], а преобладание тета-активности связано с усилением процессов торможения $[121,146,170]$. 